\title{
A ESPACIALIDADE NA CONTÍSTICA DE COLM TÓIBÍN
}

\author{
Cícero Manzan Corsi ${ }^{1}$
}

cicerocorsi@yahoo.com.br

\begin{abstract}
Resumo: Este artigo apresenta uma análise sobre a composição da espacialidade nos contos do escritor irlandês Colm Tóibín. O objeto de minha pesquisa é, principalmente, analisar como Tóibín utiliza o espaço em seus textos, assim como os procedimentos que utiliza na criação do espaço ficcional em suas narrativas, buscando estabelecer a relação desses espaços com os outros elementos narratológicos. Para realizar tal pesquisa, utilizaremos autores que estudaram a questão do espaço, como Gaston Bachelard, Maurice Merleau-Ponty e Joseph Kestner. Portanto, estudaremos o espaço nas obras ficcionais de Colm Tóibín a partir de uma teoria poética do espaço, da sua percepção e da forma como a espacialidade se relaciona diretamente com outros elementos da narrativa.
\end{abstract}

Palavras-chave: Colm Tóibín, espaço ficcional, poética do espaço, narrativa.

Abstract: This article presents an analysis about the composition of the spatiality in the stories of the irish writer Colm Tóibin. The object of my research is, mainly, analyze how Tóibin utilizes the space in his texts, as well as the procedures that he utilizes in the creation of the fictional space in its narratives, seeking establish the relation of those spaces with the others narratologics elements. For it carry out such research, we will utilize authors that studied the question of the space, as Gaston Bachelard, Maurice Merleau-Ponty and Joseph Kestner. Therefore, we will study the space in the fictional works of Colm Tóibin using as theorical basis a poetic theory of the space, of its perception and of the form as the spatiality is related straightly with others elements of the narrative.

Keywords: Colm Tóibín, space, theory of the space, narrative.

\section{CONSIDERAÇÕES}

Osman Lins, em seu importante livro intitulado Lima Barreto e o Espaço Romanesco, afirma que a narrativa é um objeto compacto e inextrincável (LINS, 1976, p. 63). Todos os fios dela se enlaçam e cada um deles reflete inúmeros outros. Apesar disso, podemos isolar um de seus aspectos e estudá-lo. Nesse sentido, seria viável nos aprofundarmos no estudo de uma obra literária, na compreensão do seu espaço ou do seu tempo. Para tanto, deve-se notar que função eles desempenham, qual sua importância e como os introduz o narrador. Nesse

\footnotetext{
${ }^{1}$ Graduado em Filosofia e em letras pela PUC-GO. Cursou também uma especialização em História Cultural pela mesma universidade. Atualmente é aluno do Mestrado em Literatura da UFG.
}

REVISTA DE ESTÉTICA E SEMIOTICA, BRASÍLIA, V. 1, N. 1 P. 1-15, JUL./DEZ. 2011 


\section{CÍCERO MANZAN CORSI}

artigo, pretendemos isolar o espaço dos contos do escritor irlandês Colm Tóibín, mostrar como ele ambienta suas narrativas, quais as relações que podemos estabelecer entre as espacialidades desses contos e outros elementos da narrativa. Para realizar tal tarefa, propomos a análise de quatro contos de Tóibín: "Famosa Gabardina Triste”, "O Uso da Razão", "Uma Canção", “Um Padre na Família”. Como aparato teórico para realizar tal análise, utilizaremos os estudos de Bachelard sobre a poética do espaço, o pensamento de Merleau - Ponty sobre a percepção e o livro The Espatiality of the Novel, de Joseph Kestner. Desse modo, analisaremos a espacialidade na contística de Colm Tóibín a partir de uma teoria poética do espaço, de um importante estudo filosófico da percepção e de uma análise profunda sobre a espacialidade e a relação dela com os outros elementos da narrativa. Segundo Osman Lins, assim como todos os recursos da arte de contar exigem do escritor discernimento e domínio, o espaço proporciona grandes possibilidades de estudo.

O professor americano Joseph Kestner mostra que o desenvolvimento de uma poética espacial para o romance envolve o uso do espaço como uma construção formal no texto e a natureza da espacialidade como método crítico para leitura de texto. Ele destaca ainda que, de acordo com uma extensa tradição que inclui Horácio e Lessing, as artes são divididas em artes temporais, que são baseadas na sucessão inerente e na irreversibilidade como o romance e a música, e artes espaciais inerentemente reversíveis e simultâneas. O conceito de espaço como uma ilusão secundária surge da ideia de que as artes temporais usam as qualidades espaciais como simultaneidade para sua própria realização, extensão e desenvolvimento. A espacialidade na arte temporal do romance envolve métodos de propriedades espaciais como volume, ponto ou simultaneidade. Em tal arte temporal, a secundária ilusão espacial significa o exercício de elementos espaciais para estender a essência natural do romance. O método espacial, ou seja, o estudo da espacialidade do romance é um recurso crítico que deve integrar algumas disciplinas incluindo Teoria da Literatura, Pensamento Científico e Práticas Artísticas Espaciais.

A partir do pensamento dos autores citados, percebemos não somente a necessidade, mas também a relevância de estudarmos a espacialidade em textos literários. Nesse sentido, este artigo propõe um estudo da espacialidade na contística de Colm Tóibín.

O escritor irlandês Colm Tóibín, em seu livro Mães e Filhos, apresenta, com peculiar habilidade, várias maneiras de ambientar suas narrativas. A constituição dos espaços é um aspecto fundamental na obra do autor e que necessita de um estudo minucioso. Afinal, através da descrição dos ambientes, Tóibín apresenta personagens e suas emoções e situa momentos de tensão no decorrer de suas narrativas.

REVISTA DE ESTÉTICA E SEMIOTICA, BRASÍLIA, V. 1, N. 1 P. 1-15, JUL./DEZ. 2011 


\title{
CÍCERO MANZAN CORSI
}

No conto intitulado "O Uso da Razão", por exemplo, logo nas primeiras páginas, percebemos que o autor utiliza a descrição do espaço da cidade vazia para descrever a tensão do protagonista anterior à visita do Tenente Cassidy. Isso ocorre porque o protagonista planejava um roubo a uma galeria de arte. Nesse ponto, a cidade é descrita cuidadosamente. Assim, percebemos que o personagem está atento, buscando perceber tudo o que está à sua volta. Observemos o seguinte trecho para percebermos mais claramente o uso que o autor faz da cidade vazia:

\begin{abstract}
A cidade era um grande vazio. Ele olhou fora da sacada de um dos top flats sobre a Charlemont Street. O desperdiçado chão largo abaixo dele estava vazio. Ele fechou os seus olhos e pensou sobre os outros flats neste andar, a maioria deles esvaziavam agora de tarde, somente alguns pequenos banheiros descobertos estavam vazios. Ele imaginou as casas nas extensões longas do subúrbio fora da cidade: Fairview, Clontarf, Malahide, ao norte; Ranelagh, Rathmines, Rathgar, ao sul. Ele pensou sobre a confiança dessas estradas sua força e sua solidez, e então ele permitiu que a sua mente vagueasse nos cômodos das casas do subúrbio, os quartos estavam vazios durante todo o dia, os comôdos abaixo estavam vazios durante toda a noite, os longos jardins de fundo, arrumados, aparados, vazios durante todo o inverno e a maioria do verão(TÓIBÍN, 2007, p. 1).
\end{abstract}

Notamos, nesse trecho, que o espaço da cidade é descrito de maneira detalhada. O personagem percebe não somente que a cidade está vazia, mas ele nota também a ausência de pessoas nos flats, nos banheiros, nas escadarias, nas casas e nos quartos. Assim, percebemos que o espaço da cidade vazia não é um simples ambiente no qual ocorre um acontecimento (a chegada do tenente Cassidy na casa do protagonista), mas, na descrição desse espaço, estão contidas a tensão do personagem, devido à visita do tenente, e a percepção dele no que diz respeito à cidade. A percepção dos personagens é uma importante fonte para a descrição dos espaços nos contos de Colm Tóibín. Como mostramos através da citação, o autor pode apresentar tensões e descrever sentimentos dos personagens mediante os ambientes descritos.

Como fundamento teórico para este estudo, utilizaremos o livro de Merleau-Ponty chamado A fenomenologia da percepção. O filósofo francês apresenta, nesse texto, a ideia de que nós percebemos o mundo a partir de nosso corpo. Merleau-Ponty, para explicar tal acepção, faz um estudo da relação dos amputados com o mundo por eles percebido. O ponto crucial dessa análise é o de que os amputados continuam percebendo o mundo como se ainda possuíssem seus membros perdidos. Sendo assim, perceber um objeto é habitá-lo, percebê-lo a partir de nosso corpo. Portanto, um objeto não é só o que uma pessoa percebe dele, é tudo aquilo que nele os outros vêem. 


\section{CÍCERO MANZAN CORSI}

Qualquer visão de um objeto por mim reitera-se instantaneamente entre todos os objetos do mundo que são apreendidos como coexistentes, porque cada um deles é tudo aquilo que os outros vêem dele. (MERLEAU-PONTY, 1999, p. 105).

As pessoas percebem o mundo de uma maneira particular e, para Merleau-Ponty, a base da percepção do mundo é o nosso próprio corpo. Apreendemos as características de um objeto através do nosso olhar. Para Merleau-Ponty, a percepção é sempre consciência perceptiva de alguma coisa e nela não se pode separar o sujeito e o objeto, como fazem as ciências naturais e as ciências sociais de base positivista. Em seu texto Fenomenologia da percepção, o filósofo francês explica que considera seu próprio corpo como seu ponto de vista sobre o mundo. Assim, tem consciência de seu corpo pelo mundo e tem consciência do mundo devido a seu corpo. Deve-se destacar que a forma como se percebe o mundo e seus fenômenos também está vinculada à cultura e à sociedade. O corpo não é inerte como uma coisa. Segundo Merleau-Ponty, a existência anônima não se esgota em um certo número de funções biológicas ou sensoriais. Ela anexa a si mesma objetos naturais, desviando-os de seu sentido imediato, ela se constrói por meio de utensílios, instrumentos. Ela se projeta no ambiente pelos objetos culturais. O corpo humano não é determinado apenas por suas funções biológicas. Ele transfigura seus poderes naturais em atividades que excedem a pura manutenção da vida. Isso se dá pelo fenômeno da expressão, do qual o corpo é sede e origem, não sendo somente um espaço expressivo, mas o próprio movimento de expressão. No mundo da linguagem, esse fenômeno se explicita quando, por uma produtividade inerente aos signos, uma intenção presente se utiliza de um vocabulário já sedimentado para apresentar um novo significado linguístico. Trata-se de uma retomada da base semântica adquirida e de um salto até uma nova significação.

Assim ocorre com o corpo, base da percepção, enquanto substrato biológico: não se trata apenas de um fator de determinação, mas de um motivo expressivo para que se consolide uma atitude geral de enformação da experiência do mundo. A percepção nunca poderia ser "neutra", imparcial ou pura. Ela sofre influências, contágios culturais e sociais. No conto "O Uso da Razão", podemos notar vários outros momentos nos quais a percepção dos personagens é utilizada como base para a descrição dos espaços, como ocorre no trecho que narra o roubo da Landsborough House. Observemos tal trecho:

No fim do corredor havia uma galeria enorme, e era onde as pinturas foram penduradas. Ele tinha os nomes das mais valiosas anotados, e foi surpreendido por quão pequeno elas eram. Se não houvesse ninguém 


\section{CÍCERO MANZAN CORSI}

olhando, ele poderia pegar uma e o colocar sob o seu casaco. Imaginou, no entanto, que havia um alarme atrás de cada pintura e que os guardas, que pareciam sonolentos, iriam, se alertados, poder mover muito rápido. Ele andou de volta ao corredor na loja pequena onde comprou cartões postais das pinturas que ele planejou roubar e cartazes do Rembrandt, que seria a joia no seu carregamento (TÓIBÍN, 2007, p. 1).

Percebemos, nesse trecho, que o autor utiliza a percepção do personagem para descrever a galeria que existia no fim do corredor e o tamanho das obras de arte. A imaginação do personagem aparece ligada à tensão do roubo. Ele acredita na existência de um alarme atrás de cada obra de arte. Percebe ainda uma pequena loja onde havia comprado os cartões postais das pinturas que iria roubar.

Outro espaço importante, nesse mesmo conto, é o estacionamento vazio no qual ele encontra os "Holandeses", os compradores dos quadros roubados. Esse espaço é importante porque podemos notá-lo várias vezes na obra de Colm Tóibín. O estacionamento vazio expressa a solidão e a insegurança do personagem devido à situação em que ele se encontra. Em “O Uso da Razão", a venda de quadros roubados para outros criminosos. Observemos o seguinte trecho:

Ele escreveu num pedaço de papel "Fique aqui" e o entregou ao mais magro logo que ele sentou-se. Ele põs o seu dedo nos seus lábios. Então saiu para o estacionamento e sentou em seu carro. Isso lhes daria algo pensar sobre, ele imaginou, Holandês ou não. O estacionamento estava vazio. Ele tomou cuidado com o movimento mais leve, mas ninguém apareceu, nenhum carro veio estacionar (TÓIBÍN, 2007, p. 1).

Percebe-se nesse trecho, inicialmente, a tensão do personagem quando ele encontra os "Holandeses". Posteriormente, notamos a tensão dele enquanto espera o comprador do quadro no estacionamento vazio, no qual ele percebe que não poderia recorrer a ninguém caso algo acontecesse.

As visitas do Tenente Cassidy à casa do protagonista representam outro aspecto importante no que tange à composição da espacialidade do conto "O Uso da Razão". Durante essas visitas o tenente pode visualizar um pouco a intimidade do personagem. Percebemos também que, na maioria das vezes, o protagonista se posiciona atrás do sofá para conversar com o tenente. Ele recorre a um canto mais íntimo, onde se sente mais seguro e tranquilo para se proteger e não cometer erros durante o diálogo. A casa, como nos mostra Bachelard, nos conforta como uma mãe. 


\section{CÍCERO MANZAN CORSI}

...o ser agora humano em que eu abrigava meu corpo nada cedeu à tempestade. A casa apertou-se contra mim, como uma loba, por momentos senti seu cheiro descer maternalmente até meu coração. Naquela noite ela foi realmente minha mãe. (BACHELARD, 1993, p. 61).

Para Bachelard, está claro, a casa nos protege, nos deixa sentir seu cheiro, abriga nossos sonhos e devaneios, sente nosso coração, portanto, em alguns momentos, é nossa mãe. A casa comporta a imaginação dos habitantes, pois suas linhas são fortes. Ela pode pertencer tanto ao passado quanto ao futuro: a casa do passado tem essa aura de proteção, a casa sonhada é a casa que tem tudo, pois é aconchegante, ao mesmo tempo em que supre todas as nossas necessidades. Ao falar da poética do espaço, Bachelard revela a intenção de dar à palavra a missão de elevar o objeto de sua análise o espaço, ao nível poético do devaneio. A fim de que isso seja possível, Bachelard apela para o serviço da imaginação, a faculdade humana por vezes esquecida que pode fazer nascer, renascer e criar novas formas de vida e de interioridade, dando às coisas o lastro humano que elas não ostentam quando ficam em sua material solidão. É-nos mostrado que há poesia nos principais espaços preferidos pelo homem. Na casa, no sótão, no porão. Numa simples gaveta. Num cofre. Num armário. Ele busca a poesia do ninho e da concha, do cantinho da casa, da miniatura, do grande e do pequeno; e, sobretudo, faz tal busca na imensidão íntima que ressoa em seu interior. $\mathrm{O}$ autor de A Poética do Espaço tem a capacidade de nos mostrar a fenomenologia do homem e sua relação com o mundo por meio de análises de textos que demonstram que há poesia dentro do homem e à sua volta.

A casa é um "valor vivo" (Bachelard, 2001, p. 73), pois, mais do que ser uma imagem homóloga ao universo, revelando seu potencial cósmico, cremos que ela é um ser habitado pelo próprio universo. Gaston Bachelard afirma ser "impossível escrever a história do inconsciente humano sem escrever uma história da casa” (BACHELARD, 2001, p. 89). Dessa forma, a casa com seus cômodos, móveis e objetos vai nos provocando sonhos e nos trazendo lembranças. Este abrigo evidente - a casa - protege-nos do frio, calor, chuva, tempestade, da noite. Mas, estando no campo das emoções, ultrapassamos o simples recordar e passamos a devanear, habitamos nossa casa oniricamente.

Devemos destacar que existem outros contos do livro Mães e Filhos que utilizam a percepção como base para a composição do espaço. Destacamos entre eles o conto "Um Padre na Família" que narra a história de uma mãe que recebe o filho, um padre que havia cometido o crime de pedofilia. A primeira frase do conto já mostra que o texto apresentará uma situação complicada. "Ela observou o céu escurecido, armando chuva" (TÓIBÍN, 2007, p. 133). Essa 


\section{CÍCERO MANZAN CORSI}

frase mostra que a mãe já pressentia uma situação ruim. O céu está negro porque alguma coisa acontecerá. Ela percebe o céu escuro. A configuração do espaço do conto torna esse aspecto fundamental. Quanto mais a situação se complica, mais escuro o céu se torna. Logicamente, esse escurecimento não ocorre devido a um problema climático. Os personagens percebem o céu escuro porque não existiria outra cor possível para o céu da família de um pedófilo. $\mathrm{O}$ espaço da cidade pequena é utilizado para mostrar a vergonha da família do protagonista diante das situações constrangedoras em que ele se vê envolvido. O céu escuro de inverno e a cidade pequena (em que as pessoas fofocam, comentam maldosamente sobre a vida alheia) geram um ambiente de tristeza e hostilidade, exatamente o sentimento da família do personagem em relação à situação que vivem.

Notamos uma relação desse conto com "O Uso da Razão ”, a posição do carro do padre Greenwood que aparece duas vezes estacionado de frente a garagem da mãe do pedófilo. Assim como em "O Uso da Razão", o carro estacionado está associado a uma situação de tensão e, nesse caso, ainda apresenta um agravante, ele está de frente à garagem da casa. Impede qualquer fuga rápida com o carro da mãe do padre.

Podemos ainda associar esse conto ao outro texto intitulado "Um Longo Inverno", no qual um filho busca pela mãe perdida durante uma nevasca. Quanto mais a esperança de encontrá-la se torna impossível, mais frio se torna o inverno. Não haveria situação em que o coração de um jovem estaria mais gelado.

Já o conto "Famosa Gabardina Triste" narra a história de uma banda que não era famosa, mas que se torna famosa. Existem vários aspectos interessantes no que diz respeito à composição da espacialidade nesse conto. O próprio início do conto é completamente determinado pela composição do espaço. A percepção de uma caixa de discos que está fora do lugar traz lembranças de uma banda de garagem da qual a personagem fazia parte quando jovem. Essa lembrança, trazida pelo deslocamento da caixa, leva a personagem a reativar a banda que fará grande sucesso. Notamos, assim, que a caixa era algo muito íntimo porque ela estava escondida em um canto da casa da personagem. Em seu livro A poética do espaço Bachelard, torna a matéria física um espaço da imaginação. O filósofo francês trabalha as imagens da vida que atraem e tocam a sensibilidade de uma vida ideal. É uma obra que valoriza os espaços "vividos", como a casa, a cabana, a gaveta, o cofre, o armário, o ninho, a concha, a miniatura e a imensidão íntima. No símbolo da casa, o homem reconhece a intimidade e a proteção. Bachelard desenvolve a ideia do abrigo, do refúgio e da proteção acendendo todas as luzes fugidias do devaneio. A casa é a maior força de integração para o pensamento, para a lembrança e para o sonho. Nessa integração, o princípio de ligação é o REVISTA DE ESTÉTICA E SEMIOTICA, BRASÍLIA, V. 1, N. 1 P. 1-15, JUL./DEZ. 2011 


\section{CÍCERO MANZAN CORSI}

devaneio. Devaneio que é sonho, fantasia, imaginação, calor íntimo, felicidade, bem-estar, alegria. Graças à casa, grande número de nossas lembranças são guardadas. A casa é um refúgio e também um arquivo. Dentro da casa ou a complementar a casa há, ainda, o porão, o sótão, os cantos da casa. Eles podem também representar pedacinhos desse refúgio e dessa memória. Trata-se do resguardo. Todo o ser humano se resguarda na proteção de sua intimidade, de sua memória, alongando indefinidamente os espaços de seus devaneios e sonhos.

Podemos notar também a relação entre a percepção dos personagens e a composição do espaço no conto "Famosa Gabardina Triste" quando a personagem Julie é encontrada morta no quarto de um hotel na Califórnia. Lisa chega para vê-la e o corpo está em um quarto escuro e gelado. Notamos claramente que, para a percepção da personagem Lisa, não existiria outra maneira na qual ela encontraria Julie morta. Qualquer lugar estaria escuro e gelado naquela ocasião.

Notamos, assim, que a percepção dos personagens é um importante elemento utilizado por Tóibín na composição do espaço de seus contos. Porém, a espacialidade dos contos atinge um âmbito muito mais complexo. Susanne Langer, em seu importante livro intitulado Sentimento e forma, faz uma distinção entre o espaço real e o espaço virtual. O que aparece no romance não é um espaço real, ele existe somente no romance. Trata-se de algo criado pelo autor. Quanto aos leitores, eles vivenciam tal aspecto virtual. As obras artísticas não expressam diretamente a experiência emocional do artista, mas uma "ideia" de emoção. A música cria uma aparência de tempo, um "tempo virtual"; na pintura, um "espaço virtual" é a primeira ilusão; os poetas criam aparências de acontecimentos, pessoas, reações emocionais, lugares, "semelhanças poéticas". Portanto, para Langer, o poeta recria o espaço.

Colm Tóibín, a partir das possibilidades artísticas da criação e recriação do espaço, cria uma unidade estética coesa entre seus textos. A maneira como ele utiliza a espacialidade é um ponto de união entre suas narrativas. Todos seus textos ficcionais apresentam espaços, ambientes como casas e cidades. Isso pode parecer meramente o óbvio, pois todo romance, pode-se dizer, apresenta espaços, de uma maneira ou de outra. O que se está destacando aqui é o fato de que há, nos contos de Colm Tóibín, uma preocupação acentuada em relação à construção espacial e que, assim, há relação dessa construção com o perceber que os personagens têm dela. Isso ajuda a moldar os textos dos quais falamos, além de lhes conferir aquela unidade referida. É, portanto, a partir dessa unidade que propomos o estudo da obra de Tóibín. 


\section{CÍCERO MANZAN CORSI}

Na obra de Colm Tóibín, o recurso do espaço é usado com considerável frequência e de forma a nos fazer acreditar que ocorre com certo padrão e propósitos. A ambientação das narrativas é, muitas vezes, utilizada pelos narradores imaginados por Tóibín como um meio para configurar personagens, apresentar suas sensações ou descrever situações psicológicas. Quando levamos isso em conta, torna-se fundamental discutir não só como os espaços são utilizados pelo autor irlandês. Também, torna-se legítimo perguntar por quais propósitos, em que situações narrativas específicas e com qual padrão de repetição ocorre a utilização. $\mathrm{O}$ espaço é uma arma utilizada pelo autor para nos envolver, mergulhar-nos em suas metáforas. Como mostra Kestner, em sua obra The Spatiality of the Novel, os espaços nos textos narrativos vão muito além de sua geometria, pois nos mergulham numa virtualidade. Nesse sentido, um estudo dos usos que um ficcionista faz do espaço em suas narrativas, como o prosador irlandês Colm Tóibín faz em seus textos, possui um caráter essencial. Compreender como tal autor utiliza os espaços em seus romance e contos é compreender como ele compõe a virtualidade em seus textos.

Joseph Kestner, em sua obra concernente à espacialidade do romance, ressalta que a espacialidade na arte temporal envolve métodos de propriedades espaciais como o volume, o ponto e a simultaneidade. A criação do espaço no romance, como uma ilusão secundária,

significa o exercício dos elementos espaciais, serve para estender a natureza temporal do romance.

Percebemos, no conto "Uma Canção", que, na composição do espaço virtual do pub, Colm Tóibín utiliza a percepção do personagem Noel para relatar detalhadamente o espaço. A partir desse momento, não lemos o conto de uma maneira distanciada, mas parecemos inseridos dentro da virtualidade do espaço do pub. Observemos o trecho em que o autor descreve o pub:

Logo que ele entrou a cervejaria, viu na fresta da janela alguém que tocava o melodion, a outra rabeca, reconhecendo-o com a pancada mais minúscula dos olhos e um franzir de testa. Uma multidão tinha reunido ao redor deles, dois outros violinistas e uma mulher jovem tocando a flauta. A mesa na frente deles estava carregada com copos cheios e meio-cheios. (TÓIBÍN, 2007, p. 42).

Notamos, nesse trecho, que o autor cria um espaço virtual. Nós leitores podemos visualizar a ação como se estivéssemos sentados no pub, estamos inseridos no espaço virtual. Joseph Kestner compara essa maneira de compor o espaço com a pintura, a escultura e a arquitetura. Seria como se o autor pintasse o espaço do texto. O primeiro aspecto livre e estático da cena tem qualidades importantes da pintura, o efeito de estar dentro da moldura é tão extremo que o leitor é encorajado a sentir que ele entrou na figura (KESTNER, 1978, p. REVISTA DE ESTÉTICA E SEMIOTICA, BRASÍLIA, V. 1, N. 1 P. 1-15, JUL./DEZ. 2011 


\section{CÍCERO MANZAN CORSI}

71). Esse tipo de cena mostra o grande poder da pintura para atingir poderosos efeitos na narração. A técnica de enquadramento não somente enfatiza a qualidade espaço pictórica da intriga, mas também funções em outro modo atemporal. Quando o autor utiliza o recurso do enquadramento, o elemento espacial de uma narrativa é óbvio e se torna um contexto. Um elemento de uma grande narrativa.

Um modo alternativo de caracterização espacial da narrativa existe no volume escultural. Ele está relacionado a três ideias bem estabelecidas na tradição da crítica sobre escultura. Entre elas, temos estátuas que parecem falar, a escultura que envolve uma ilusão temporal secundária e os personagens na literatura têm uma aberta relação com objetos esculpidos. A crença na habilidade de estátuas falarem sugere uma grande ilusão secundária criada pela arte espacial. Kestner cita o caso do David de Donatelo, na qual a figura do herói fica sobre a cabeça de Golias enquanto ainda está segurando a pedra. Sendo assim, a estátua ainda está em movimento, ela parece mostrar que David matará Golias com a pedra.

A palavra virtual pode ser usada para designar a forma da secundária ilusão espacial. Virtual significa o potencial das artes espaciais que estão em estado secundário do texto. Normalmente, essas composições estão ligadas às cenas e aos lugares (KESTNER, 1978, p. 72).

Colm Tóibín descreve o bar e a cena na qual todos os outros elementos do texto estão envolvidos como se o estivesse pintando. O espaço como conhecemos não tem forma. Ele é amorfo, em nossas vidas ativas, trata-se de um substrato de nossas experiências. Já o espaço harmoniosamente organizado numa pintura não é o espaço da experiência, conhecido pela visão e pelo tato. Ele é uma questão inteiramente visual, uma ilusão. A ilusão primária de toda arte plástica. Esse espaço não tem continuidade com o espaço que vivemos. Ele é limitado pela moldura, pelos vazios que o circundam, ou outras coisas incongruentes que o isolam. O espaço virtual é inteiramente independente, um sistema total e auto-suficiente.

Outro tipo de espaço destacado por Kestner é o genidêntico. Ele está relacionado ao conceito de genidentidade desenvolvido na física por Reinchenbach. A interpretação da obra literária, como observa Genette, não deve se limitar somente à essência temporal da mesma, mas deve abarcar também a espacialidade. O livro seria capaz de criar sua própria dinâmica ao produzir uma interpenetração do texto e do interpretador. A espacialidade genidêntica recebe esse nome porque está relacionada à teoria da genidentidade. Esta torna possível o conceito de individual. A identidade do tempo entre o trabalho da arte e seu interpretador repousa no eclipse da distância de seus espaços separados. 


\section{CÍCERO MANZAN CORSI}

A natureza da relatividade espacial na arte temporal da literatura é esclarecida pela teoria da genidentidade desenvolvida por Kurt Lewin em 1922. De acordo com Hans Recheinbach, em Space and Time, a genidentidade torna possível o conceito de individual que lembra a duração idêntica da passagem do tempo (KESTNER, 1978).

Kestner destaca que uma partícula A pode ser considerada genidêntica com A2 e A3 tão bem como B2, C3 e D4. Para o propósito da teoria literária e da interpretação, um ambiente pode marcar vários significados dessas partículas. Se alguém lê dois textos, A e B, o conceito de genidentidade mostra como ambos podem se lembrar de maneira individual e múltipla. Similarmente, se A é um texto, B é um campo dinâmico descomplicado pela distância existente entre os textos. O texto e seu interpretador ocupam o mesmo espaço, o campo dinâmico, em uma relação atemporal. Porém, Kestner destaca que o conceito de genidentidade tem grande importância e observa que diferentes estados podem ser genidênticos somente se eles estão causadamente relacionados. Dois bons exemplos de espaços genidênticos são as prisões Mountjoy Jail e Lanfad descritas por Tóibín no conto "The use of Reason". Esses dois espaços são genidênticos à várias outras prisões da história da literatura e de nossa vida real. Eles também são genidênticos entre si. Para notarmos essa genidentidade, observemos o trecho em que o autor descreve Mountjoy Jail:

Ele tinha se sentido assim quando cumpriu a sua única sentença adulta em
Mountjoyjail. Ele tinha perdido a sua esposa e sua primeira criança, e se
perdeu indo onde ele gostava de ir, mas não se importava de estar cada noite,
ele gostava de ter todo o tempo para si. Nada imprevisível ocorreu e que o
fez contente; os outros prisioneiros souberam não chegar tão próximos a ele.
Ele odiou a comida, mas ele não prestou nenhuma atenção a isso, e ele odiou
os parafusos, mas eles souberam cuidar dele bem. Ele assegurou-se que
quando a sua esposa veio em visitas uma vez por semana que ele não
demonstrasse nada, nenhuma emoção, nenhum sentido de quão solitário e
isolado ele era às vezes. (TóIBÍN, 2007, p. 10).

Notamos que o protagonista do conto, como boa parte dos prisioneiros que ouvimos falar, perdeu muitas coisas importantes como a esposa, o filho, a liberdade de ir e vir. $\mathrm{Na}$ prisão, a comida era ruim, ele recebia visitas somente uma vez por semana. Portanto, a descrição do espaço de Mountjoy Jail é feita a partir da genidentidade entre ela e várias outras prisões que conhecemos através da experiência ou da leitura.

Logo no parágrafo seguinte, Tóibín descreve a prisão de Landfad que era em Midlands. Nessa prisão, o personagem se sentia sufocado pelo lugar que era frio e, como qualquer prisão que ouvimos falar, não era amigável. O protagonista presidiário nunca chorou 


\section{CÍCERO MANZAN CORSI}

e imaginava que não estava em lugar nenhum. Percebemos, a partir do que foi discutido, que Tóibín compõe os espaços das duas prisões a partir de uma genidentidade entre elas e os vários espaços semelhantes que conhecemos. Se não lemos cuidadosamente o texto, Mountjoy Jail e Lanfad parecem até mesmo ser a mesma prisão.

A composição do espaço a partir da genidentidade pode ser percebida também nos romances de Colm Tóibín. No livro The Heather Blazing, Colm Tóibín apresenta uma história que se distancia um pouco de seus outros textos pela temática. Nesse livro, o autor não trata, por exemplo, do problema da homossexualidade, mas apresenta, de qualquer forma, uma história sobre conflitos e tensões humanas. O livro narra a história de um juiz em luta com problemas sociais e profissionais. Nesse texto, Tóibín analisa as relações do personagem com sua esposa e seus filhos. Quanto à espacialidade, o texto de Tóibín também apresenta aspectos interessantes. Na primeira cena do livro, por exemplo, a expectativa do personagem é denotada a partir da descrição detalhada do espaço. Observemos o seguinte trecho:

Eamon Redmond ficou na janela olhando o rio que estava profundamente marrom depois dos dias de chuva. Ele observava a cor, a mistura de lama e água, e as pequenas correntes e bolsos de movimento dentro do fluxo. Era uma manhã de sexta-feira no fim de julho; o trânsito era pesado nos cais. Mais tarde, quando o tribunal tinha terminado ele voltaria outra vez e olharia para fora mais uma vez na luz cinzenta aquosa sobre as casas na margem do rio e espera pela calma, quando os carros e caminhões tinham desaparecido e Dublin era calma. (TÓIBÍN, 1992, p. 3).

Essa detalhada descrição do espaço tem uma relação direta com a tensão do personagem antes de uma audiência de julgamento. Redmond aparece apoiado em uma janela e, a partir dessa posição, ele observa cada detalhe do espaço, a cor da água, o movimento das correntes, coisas que não observamos normalmente em nosso cotidiano. Devemos, ainda, relacionar o espaço apresentado no texto com o conceito de espaço genidêntico de Kestner, pois notamos claramente que Tóibín utiliza a maneira como identificamos uma janela, um rio de água turva, uma cidade de grande tráfego e o silêncio da noite de uma grande capital para configurar um espaço genidêntico. Podemos falar ainda, junto a Kestner e Langer, que o espaço composto pelo personagem é um espaço virtual que vivenciamos mediante a relação com a obra de arte. Percebe-se que o espaço é composto a partir da visão do personagem, é aquilo que o personagem vê a partir de sua própria perspectiva.

Devemos notar que a janela também pode ser relacionada à casa bachelardiana, pois o autor ressalta que o olhar pela janela do edifício possui grande força e importância. $\mathrm{O}$ personagem de Tóibín não olhava simplesmente pela janela, mas, a partir dali, tinha uma REVISTA DE ESTÉTICA E SEMIOTICA, BRASÍLIA, V. 1, N. 1 P. 1-15, JUL./DEZ. 2011 


\section{CÍCERO MANZAN CORSI}

perspectiva do mundo. O olhar pela janela simbolizaria a percepção do mundo a partir de sua intimidade, pois é a partir de nossa intimidade que percebemos o mundo. É através de tal olhar que é possível relacionar o mundo e os devaneios.

A partir da análise dos contos "Famosa Gabardina Triste", "O Uso da Razão", "Uma Canção" e "Um Padre na Família", notamos que a composição do espaço é um importante elemento da contística de Colm Tóibín. Se analisarmos toda obra o autor com cuidado, perceberemos que a composição da espacialidade a partir da percepção dos personagens, a presença de espaços virtuais e genidênticos e as composições poéticas do espaço são elementos que aparecem constantemente nas narrativas de Colm Tóibín. Podemos citar, como exemplo, o romance $O$ Mestre. Em seu romance sobre a biografia de Henry James, Tóibín utiliza vários espaços da biografia do personagem para compor seu texto. $\mathrm{O}$ autor de $O$ mestre apresenta os mesmos sonhos de James, os espaços compostos pelos lugares pelos quais ele viajou e, principalmente, a mansão chamada de Lamb House que foi o lugar em que James mais gostou de morar e escrever. Logo no primeiro capítulo, o autor cita um "adorável negrume", um lugar permeado por uma claridade que, para James, era o lugar perfeito para o sono. Nesse momento, podemos estabelecer novamente a relação entre o espaço e a percepção. O adorável negrume é percebido pelo personagem Henry James a partir de seu corpo. Uma escuridão que agrada o corpo durante o sono, que o permite dormir bem.

Ainda no primeiro capítulo, Tóibín cita a cidade de Londres. Para James, esta cidade era um lugar em que as pessoas não possuíam um eu oculto e secreto, a menos que elas mesmas declarassem isso. Podemos observar, ainda no mesmo capítulo, a relação do personagem com Paris. O personagem aparece distanciado de casa, daquilo que era a sua intimidade. Paris era um lugar em que as pessoas dissimulavam aquilo que lhes era mais importante, elas se sentiam sempre vigiadas pelos romancistas. Desse modo, a Paris literária agia como participante de um jogo da simulação e do disfarce.

Em $O$ mestre, o espaço mais importante é a chamada Lamb House, uma casa que foi adquirida por Henry James em Rye. A Lamb House não é somente uma mansão em que é depositada toda a intimidade do escritor, mas é o lugar perfeito para a produção artística. $\mathrm{O}$ jardim de inverno da mansão é descrito como o espaço ideal para se produzir literatura. Podemos estabelecer uma relação direta entre esse espaço e a casa tal como na possibilidade bachelardiana. A Lamb House é o canto do mundo de Henry James, ela abriga seus devaneios, o deixa sonhar em paz. Segundo Bachelard, para um estudo fenomenológico dos valores de intimidade do espaço interior, a casa é, evidentemente, um espaço privilegiado (BACHELARD, 2001, p. 23). A casa é um elemento que pode viabilizar a compreensão REVISTA DE ESTÉTICA E SEMIOTICA, BRASÍLIA, V. 1, N. 1 P. 1-15, JUL./DEZ. 2011 


\section{CÍCERO MANZAN CORSI}

acerca da poética do espaço e do levantamento de imagens. Devemos ressaltar que ela abriga espaços ainda muito mais íntimos - como o quarto e o canto - e cada espaço, nesse sentido, nos possibilita um devaneio ainda mais profundo. Podemos relacionar tais aspectos ao jardim de inverno de Henry James. Este é o lugar onde o escritor consegue viajar em todos seus devaneios e, exatamente por essa razão, é ideal para o trabalho da escrita.

Outro espaço importante, citado no capítulo de $O$ mestre que trata do mês de Janeiro no ano de 1895, é o lugar que James reservou para si no teatro em que assistiu à representação de sua primeira peça. A percepção aparece aqui de duas maneiras: primeiramente, a partir da relação do personagem com os amigos e familiares que estavam em todos os assentos perto dele, criando um espaço em que se sentia seguro, como se em sua própria casa. Quanto aos desconhecidos, ele os isolou na galeria acima. Em segundo lugar, James está posicionado em um lugar de onde consegue perceber a reação do público que assiste à peça, possibilitando, nesse "ver", que ele também seja "visto", o que faz com que, ao "ver" o fracasso de sua peça, James também seja "visto" como um corpo oprimido por seu fracasso como dramaturgo.

Sendo assim, a ambientação de Colm Tóibín é um grande problema que demanda a composição de um trabalho mais longo para percebermos todos os detalhes da ambientação das narrativas do premiado escritor.

Em outro romance de Tóibín, $O$ sul, a personagem Katherine Proctor, uma mulher oprimida pela estrutura tradicional do casamento, na conservadora Irlanda católica da década de 50, cansada das limitações impostas por essa sociedade e insatisfeita com o casamento, toma uma decisão bastante drástica: ela abandona o marido e o filho e muda-se para Barcelona, na Espanha. Desse modo, logo no início do livro, temos uma primeira relação da personagem com um dos espaços. Katherine Proctor abandona sua casa, seu país, a Irlanda católica, rompendo com os espaços íntimos (o casamento, o marido e o filho, a família, enfim), e vai para outro país, outra cultura, em busca de outra intimidade, outras relações.

Quando a personagem chega à Barcelona, ela conhece Jorge, um artista plástico. Nesse momento, no texto de Tóibín, tem início um interessante processo de reconstrução da intimidade da personagem. A personagem não só passa a morar em uma nova cidade, mas ela decide morar na casa de Jorge. A descrição da casa para qual Jorge a leva é um ponto fundamental do texto: possui uma péssima aparência exterior, mas o espaço interior é enorme. A casa poderia ser o lugar onde residiria a intimidade dos dois personagens, ele era grande o suficiente para refugiar e proteger Katherine Proctor.

Percebemos, a partir da análise dos textos de Colm Tóibín, que a espacialidade é um elemento essencial dos contos de Tóibín. Através desse elemento, o escritor consegue realizar REVISTA DE ESTÉTICA E SEMIOTICA, BRASÍLIA, V. 1, N. 1 P. 1-15, JUL./DEZ. 2011 


\section{CÍCERO MANZAN CORSI}

muito mais que uma simples ambientação de seus textos. Os espaços dos textos de Tóibín ajudam o leitor a compreender a percepção dos personagens. São elementos com significados poéticos que apresentam as emoções dos personagens e inserem os leitores na virtualidade dos textos narrativos.

\section{REFERÊNCIAS}

BACHELARD, Gaston. Poética do Espaço. São Paulo-SP: Martins Fontes, 2001.

MERLEAU-PONTY, Maurice. Fenomenologia da Percepção. São Paulo-SP: Martins Fontes, 2006.

LINS, Osman. Lima Barreto e o Espaço Romanesco. São Paulo-SP: Editora Ática,1976.

LANGER, Susane. Sentimento e Forma. São Paulo-SP: Editora Perspectiva, 2003.

KESTNER, Joseph. The Spatiality of the Novel. Detroit: Wayne State University Press, 1978.

TÓIBÍN, Colm. Mothers and Sons. New York: Scribner, 2007.

The Heather Blazing. New York: Penguin Books, 1992.

. O Mestre. Lisboa: Dom Quixote, 2007.

. A luz do farol. Rio de Janeiro-RJ: Companhia das Letras, 2004.

. History of the night. Dublin: Pan Macmillan, 2002.

O sul. São Paulo-SP: Record, 1999.

Brooklyn. New York: Scribner, 2009.

. The Empty Family. York: Scribner, 2011. 